Article

\title{
Endogenous 3-Iodothyronamine (T1AM) and Synthetic Thyronamine-Like Analog SG-2 Act as Novel Pleiotropic Neuroprotective Agents through the Modulation of SIRT6
}

\author{
Lorenza Bellusci ${ }^{1, \dagger}$, Massimiliano Runfola ${ }^{2, \dagger}$, Vittoria Carnicelli ${ }^{1}$, Simona Sestito ${ }^{1}$, \\ Federica Fulceri ${ }^{3}$, Filippo Santucci ${ }^{4}$, Paola Lenzi ${ }^{5}$, Francesco Fornai ${ }^{5,6} \oplus$, \\ Simona Rapposelli ${ }^{2,7} \mathbb{1}$, Nicola Origlia ${ }^{8}$, Riccardo Zucchi ${ }^{1}$ and Grazia Chiellini ${ }^{1, *}$ \\ 1 Laboratory of Biochemistry, Department of Pathology, University of Pisa, 56100 Pisa, Italy; \\ lorenza.bellusci@student.unisi.it (L.B.); vittoria.carnicelli@unipi.it (V.C.); simona.sestito@for.unipi.it (S.S.); \\ riccardo.zucchi@med.unipi.it (R.Z.) \\ 2 Laboratory of Medicinal Chemistry, Department of Pharmacy, University of Pisa, 56126 Pisa, Italy; \\ massimiliano.runfola@farm.unipi.it (M.R.); simona.rapposelli@unipi.it (S.R.) \\ 3 Department of Clinical and Experimental Medicine, University of Pisa, 56100 Pisa, Italy; \\ federica.fulceri@unipi.it \\ 4 Sant'Anna School of Advanced Studies, 56127 Pisa, Italy; f.santucci@santannapisa.it \\ 5 Unit of Human Anatomy, Department of Translational Research and New Technologies in Medicine and \\ Surgery, University of Pisa, 56126 Pisa, Italy; paola.lenzi@med.unipi.it (P.L.); \\ francesco.fornai@med.unipi.it (F.F.) \\ 6 IRCCS Neuromed, 86077 Pozzilli (IS), Italy \\ 7 Interdepartmental Research Centre of Ageing Biology and Pathology, University of Pisa, 56126 Pisa, Italy \\ 8 National Research Council (CNR), Institute of Neuroscience, 56124 Pisa, Italy; nicola.origlia@in.cnr.it \\ * Correspondence: grazia.chiellini@unipi.it; Tel.: +39-050-221-86-62 \\ $\dagger$ These authors have contributed equally to this work.
}

Received: 30 November 2019; Accepted: 25 February 2020; Published: 26 February 2020

check for updates

\begin{abstract}
T1AM) and the recently developed analog SG-2 are rapidly emerging as promising multi-target neuroprotective ligands able to reprogram lipid metabolism and to produce memory enhancement in mice. To elucidate the molecular mechanisms underlying the multi-target effects of these novel drug candidates, here we investigated whether the modulation of SIRT6, known to play a key role in reprogramming energy metabolism, might also drive the activation of clearing pathways, such as autophagy and ubiquitine-proteasome (UP), as further mechanisms against neurodegeneration. We show that both T1AM and SG-2 increase autophagy in U87MG cells by inducing the expression of SIRT6, which suppresses Akt activity thus leading to mTOR inhibition. This effect was concomitant with down-regulation of autophagy-related genes, including Hif1 $\alpha$, p53 and mTOR. Remarkably, when mTOR was inhibited a concomitant activation of autophagy and UP took place in U87MG cells. Since both compounds activate autophagy, which is known to sustain long term potentiation (LTP) in the entorhinal cortex (EC) and counteracting AD pathology, further electrophysiological studies were carried out in a transgenic mouse model of AD. We found that SG-2 was able to rescue LTP with an efficacy comparable to T1AM, further underlying its potential as a novel pleiotropic agent for neurodegenerative disorders treatment.
\end{abstract}

Keywords: 3-iodothyronamine (T1AM); thyronamine-like analogs; multi-target directed ligand; neurodegeneration; Sirt6; autophagy; ubiquitine-proteasome; long term potentiation (LTP); mhAPP mouse model 


\section{Introduction}

Growing evidence suggests the presence of a strong association between obesity and neurodegeneration [1-3]. A number of pathways may translate the occurrence of obesity into abnormal brain structure and function [4]. When these pathways, such as the PI3K/Akt signaling, are altered brain damage related to neuronal oxidative stress occurs. This stressful condition recruits the endoplasmic reticulum (ER) and mitochondria, which are subcellular structures specifically altered following PI3K/Akt dysfunction ultimately producing neuronal loss [5].

Sirtuins belong to a highly conserved protein family of seven members (SIRT1-7). These proteins guard homeostasis by sensing the energy status and cope with energy needs. In fact, sirtuins finely tune the availability of specific cell components. At the same time, the activity of sirtuins mitigates a variety of steps involved in neurodegeneration. Among the seven mammalian sirtuins, SIRT6 plays an essential role in regulating metabolic homeostasis, stress resistance and lifespan [6,7]. In addition, SIRT6 is critical to maintain genomic stability in the brain and its loss leads to toxic Tau stabilization and phosphorylation [8]. Therefore, SIRT6 could be relevant in Alzheimer's disease (AD) and age-related neurodegeneration.

All these findings suggest that specific drugs acting on sirtuins level may exert broad therapeutic potential against interlinked age-related diseases, such as obesity and various neurodegenerative disorders (NDDs).

Recently, evidence was provided that 3-iodothyronamine (T1AM), an endogenous component of the thyroid endocrine system $[9,10]$, reprogrammed altered metabolism when exogenously administered to obese mice at pharmacological doses $(10 \mathrm{and} 25 \mathrm{mg} / \mathrm{kg}$ ) [11]. This effect was based on the activation of SIRT6-mediated pathways [12], which in turn actively rescued fatty acid and glucose metabolism. We found that these effects led to a significant weight loss, which was independent from food consumption [11,12]. Notably, our group also provided the first evidence that when systemically administered to mice at submicromolar doses T1AM and recently developed thyronamine-like analogs were able to improve learning and memory [13]. In addition, in the same study in vitro experiments revealed the ability of these compounds to potently induce autophagy in human glioblastoma cell lines (U87MG) via inhibition of mTOR phosphorylation by the PI3K-AKT-mTOR pathway [13].

Taken together, these data indicate that further studies may be pursued to explore the potential of T1AM and synthetic thyronamine-like analogs to act as pleiotropic agents [14] for the treatment of interlinked diseases such as obesity and neurodegeneration.

Thus, the present work was designed to investigate in more detail the molecular mechanisms through which T1AM and recently developed thyronamine-like analogs (namely, SG-1 and SG-2, Figure 1), could produce a SIRT6 activation bridging autophagy, weight loss and neuroprotection $[12,13]$.

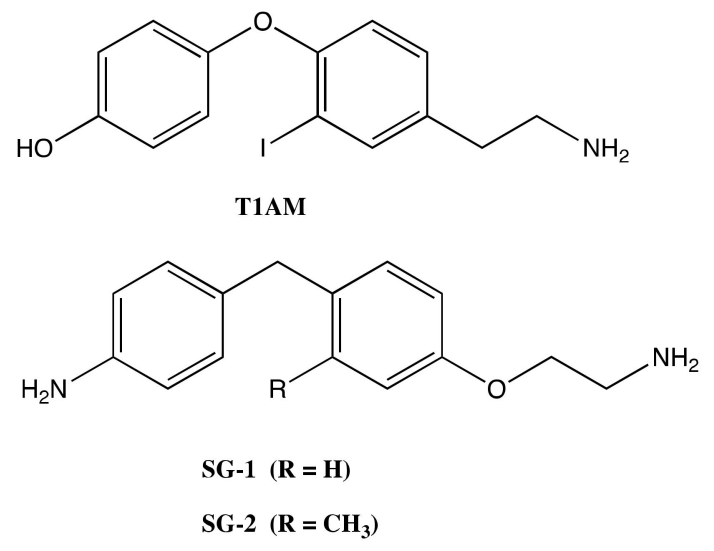

Figure 1. Structures of 3-iodothyronamine (T1AM) and thyronamine-like analogs SG-1 and SG-2. 
The present investigation was further motivated by recent findings, which indicate that the two major clearing pathways, namely autophagy and ubiquitine proteasome (UP), considered as independent for long time, converge at the level of single organelles named autophagoproteasomes following mTOR inhibition. Such a merging when considered at functional level might empower protein homeostasis and cell clearing $[15,16]$. In line with this evidence, we included an experimental part where the merging between autophagy and UP was investigated under the effects of T1AM and thyronamine-like analogs SG-1 and SG-2.

In addition, previous studies have shown that administration of T1AM is able to rescue $\beta$-Amyloid induced neuronal dysfunction in wild type mice [17], and more recently, the protective effect of T1AM against neuronal plasticity impairment has been further confirmed in transgenic AD mice [18] (hAPP-J20, also denoted mhAPP mice), paving the way to the identification of new pharmacological targets to retard AD progression [19].

In this regard, with the aim to increase the therapeutic options for this incurable disease, we explored the ability of SG-2, already considered as a fully functional mimic of T1AM for behavioral and metabolic effects $[13,20,21]$, to rescue $\beta$-amyloid neuronal dysfunction in mhAPP mice.

\section{Results}

\subsection{Effects of SG-1, SG-2 and T1AM on the Expression of Autophagy-Related Genes}

Autophagy is an important metabolic process which wraps unnecessary intracellular components, such as lipids, misfolded proteins, and dysfunctional organelles, in double-membraned vesicles, defined as autophagosomes, which are then transported to lysosomes for degradation and recycling, thus maintaining essential cellular viability in response to diverse stresses [22-24].

Previous studies have shown that mTOR can be inhibited by SIRT6 to promote autophagy in neuronal cells under oxidative stress [25]. Other groups have also demonstrated that SIRT6 induces autophagy by attenuating AKT/mTOR signal cascades in normal cells [26,27]. Above all, it seems that SIRT6 positively regulates cell autophagy by targeting mTOR signaling pathway.

In the present study, using the quantitative polymerase chain reaction assay (qPCR) we found that SIRT6 was highly upregulated in U87MG cells treated for 24 h with (1 $\mu \mathrm{M}) \mathrm{T} 1 \mathrm{AM}$, SG-1 or SG-2 (Figure 2a). Recent studies [28] have demonstrated that SIRT6 regulates glucose homeostasis by inhibiting the hypoxia-inducible transcription factor (Hif1 $\alpha$ ), a key mediator of cellular adaptation to nutrient and oxygen stress. Our gene expression study indicated a reduced expression of Hif1 $\alpha$ in U87MG cells after treatment with $(1 \mu \mathrm{M})$ T1AM, SG-1 or SG-2 (Figure 2b).

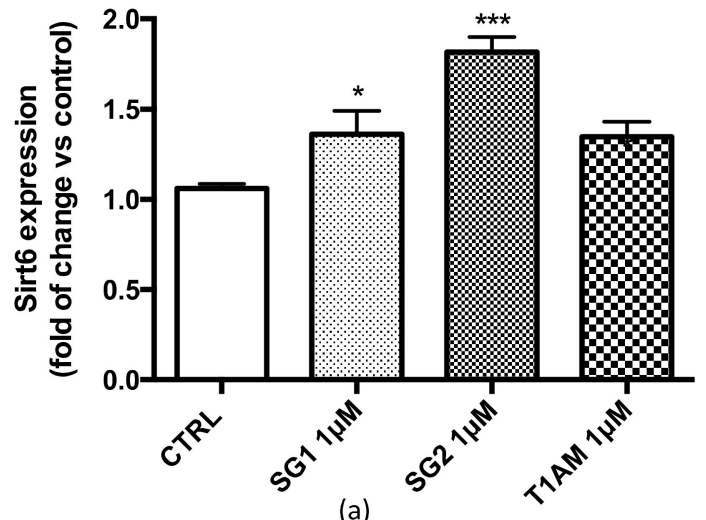

(a)

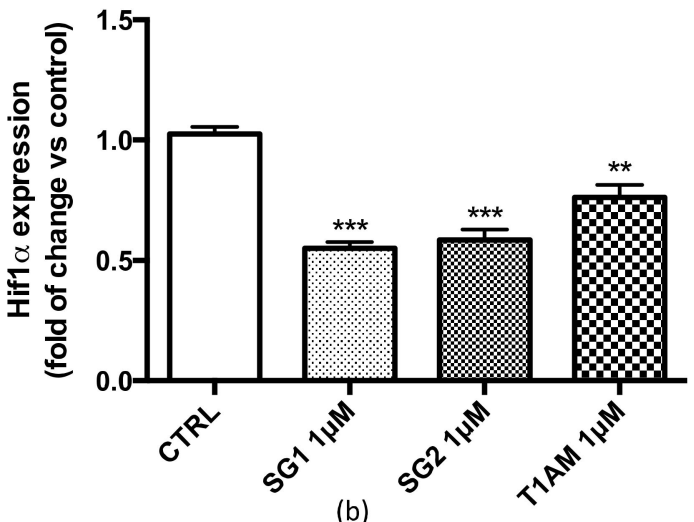

(b)

Figure 2. Cont. 


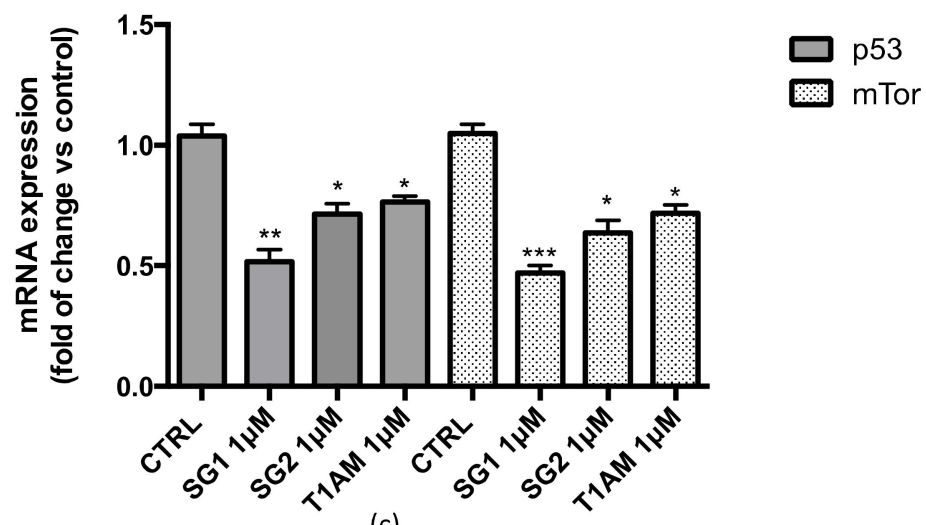

Figure 2. Effect of SG-1, SG-2 or T1AM treatment on the expression of autophagy ATG target genes in U87MG cells. After 24h incubation of U87MG cells with $1 \mu \mathrm{M}$ SG-1, SG-2 or T1AM total RNA was extracted, and the relative mRNA quantification of Sirt6 (a), Hif1 $\alpha(\mathbf{b})$, or p53 and mTOR (c) was performed by real-time RT-PCR. The data are expressed as fold changes vs control and represent the mean \pm SEM of three different experiments $(n=3)$, each performed in duplicate. Statistical significance was determined using a one-way ANOVA followed by a Dunnett's post-test: ${ }^{*} P \leq 0.05,{ }^{* *} P \leq 0.01$, $* * * P \leq 0.005$ vs control.

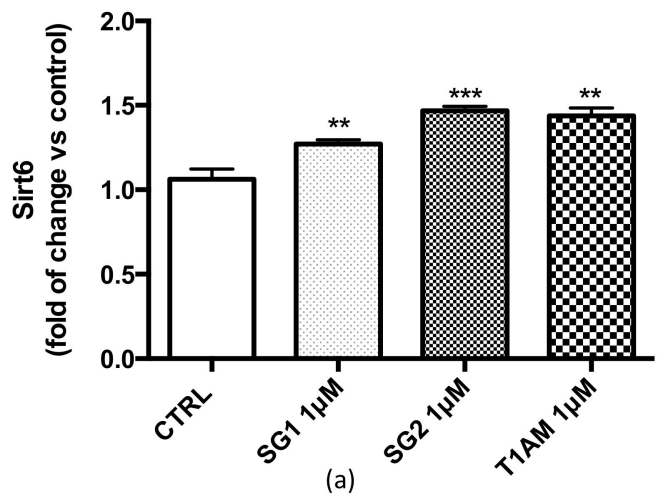

(a)

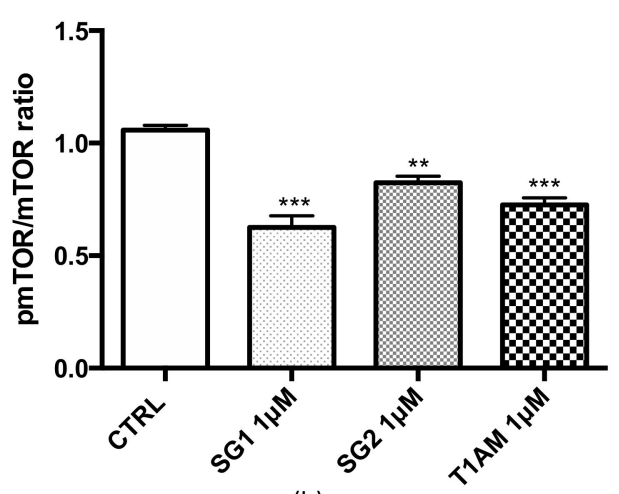

(b)

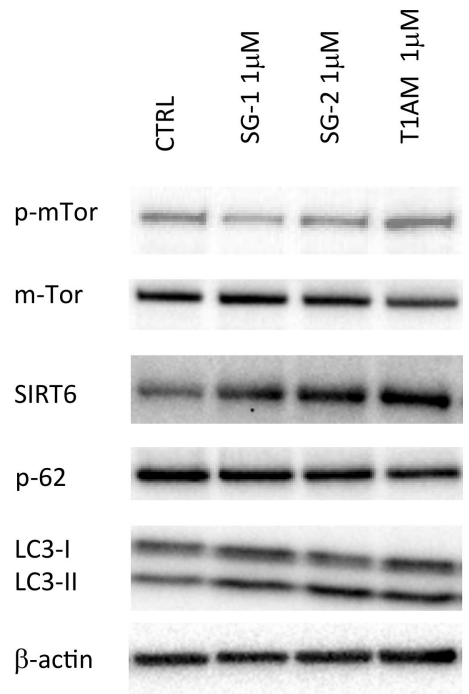

(c)

Figure 3. Western blot quantification of SIRT6 (a) and p-mTOR/mTOR (b) in U87MG cells exposed for $24 \mathrm{~h}$ to $(1 \mu \mathrm{M}) \mathrm{SG}-1$, SG-2 or T1AM. $\beta$-actin was used as an internal control. Results represent the mean \pm SEM of three different gels $(n=3)$. ${ }^{* *} P \leq 0.01,{ }^{* * *} P \leq 0.005$ versus vehicle treated cells (CTRL). Representative western blots are shown in Panel c.

Known as a 'guardian of the genome' [29], p53 protein plays a crucial role in the development of neurodegenerative diseases, and high levels of p53 have been observed in the brain of AD, Parkinsons's disease (PD) and Huntington's disease patients [30]. Interestingly, inactivation of p53 by deletion, 
depletion or inhibition has been reported to trigger autophagy [30], and several distinct autophagy inducers, including rapamycin, stimulate the rapid degradation of p53 [31]. Here we tested the effects of SG-1, SG-2 and T1AM on the expression of p53 and mTOR in U87MG cells. Our results revealed a concomitant significant decrease of p53 and mTOR expression in U87MG cells after treatment with $1 \mu \mathrm{M}$ T1AM, SG-1 or SG-2 (Figure 2c).

\subsection{Effects of SG-1, SG-2 and T1AM on the Expression of SIRT6 and mTOR}

The transcriptional analysis results indicated that in U87MG cells a $24 \mathrm{~h}$ treatment with $1 \mu \mathrm{M}$ T1AM, SG-1 or SG-2 induced a significant up-regulation of Sirt6 and a parallel down-regulation of mTOR. Protein expression studies by Western blotting confirmed over-expression of sirtuin 6 (SIRT6) (Figure 3a) and inhibition of mTOR phosphorylation (Figure 3b) in U87MG cell lysates (full length Western blots for Figure $3 \mathrm{c}$ are shown in Supplementary Figure S1). In agreement to our previous findings (13), increased level of LC3II, a marker for autophagosome formation, and decreased p62 protein level, a marker for autophagic protein degradation were also observed (Figure 3c), thus confirming the efficacy of T1AM and thyronamine-like analogs, SG-1 and SG-2, as autophagy inducers in U87MG cells.

In addition, cellular viability was determined using the MTT colorimetric assay. No significant alterations of cell viability were observed in U87MG cells treated for 24 and $72 \mathrm{~h}$ with 1 and $5 \mu \mathrm{M}$ T1AM, SG-1 or SG-2 as compared to vehicle treated cells (0.1\% DMSO) (Figure 4).
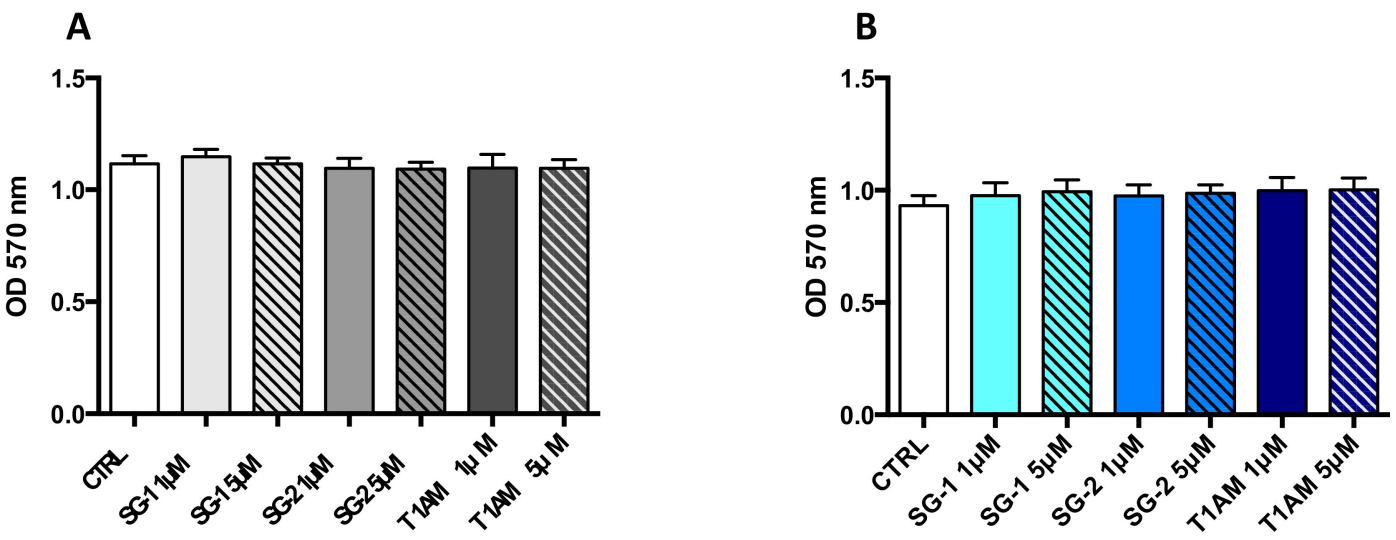

Figure 4. Compounds SG-1, SG-2 and T1AM do not promote toxicity in U87MG cells. Cell viability after $24 \mathrm{~h}(\mathbf{A})$ and $72 \mathrm{~h}$ (B) of incubation with compound SG-1, SG-2 or T1AM. (1 and $5 \mu \mathrm{M})$ was assessed by MTT assay. The data represent the mean \pm SEM of three independent experiments, each performed in triplicate $(n=3)$.

\subsection{Effects of SG-1, SG-2 and T1AM on Cell Clearing Systems}

As previously reported, T1AM and synthetic analogs SG-1 and SG-2 were found to produce a time-dependent recovery of autophagic activity in U87MG cells, due to the down-regulation of mTOR [13]. Recently, Lenzi et al. provided compelling morphological evidence that the two major clearing pathways of eukaryotic cells (autophagy and proteasome), converge at the level of single organelles named autophagoproteasomes [15]. At this level, the regulation of all components seems to rely on the status of mTOR activity. In fact, a dose dependent increase of these organelles was observed when the mTOR inhibitor rapamycin was administered [15].

In the present study, we tried to find out whether T1AM and synthetic analogs SG-1 and SG-2 have the ability to induce the occurrence of autophagoproteasome. Transmission electron microscopy (TEM) analysis confirmed a time dependent increase of autophagy vacuole density in U87MG cells exposed to the treatment with $1 \mu \mathrm{M}$ T1AM, SG-1 or SG-2, which generally leads to a roughly 3 -fold increase as compared to U87MG cells in baseline conditions (Figure 5). 


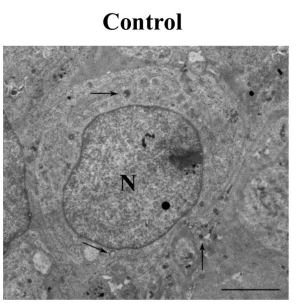

(a)

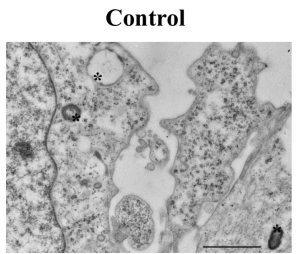

(e)

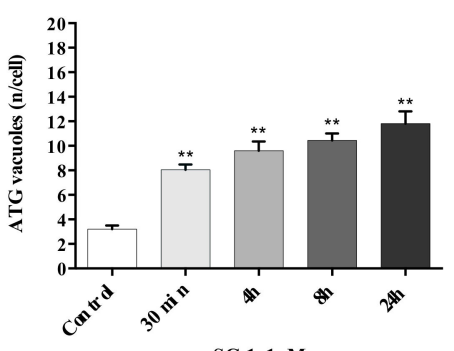

(i)

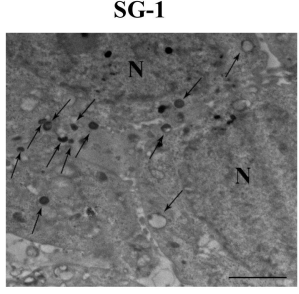

(b)

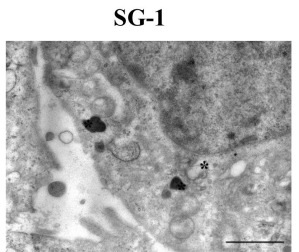

(f)
SG-2

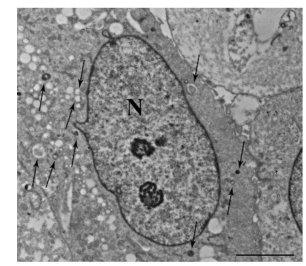

(c)

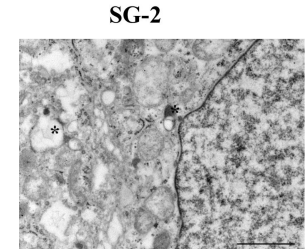

(g)

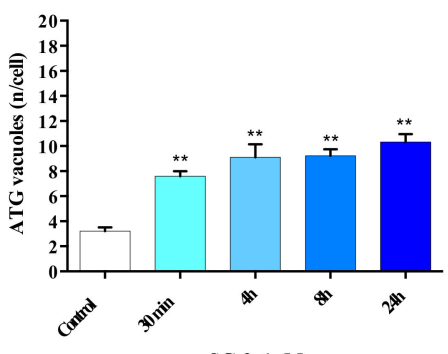

(j)
T1AM

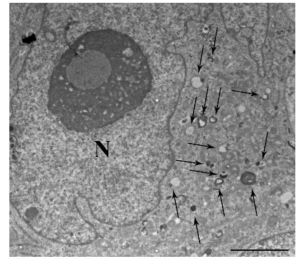

(d)

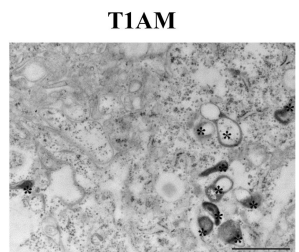

(h)

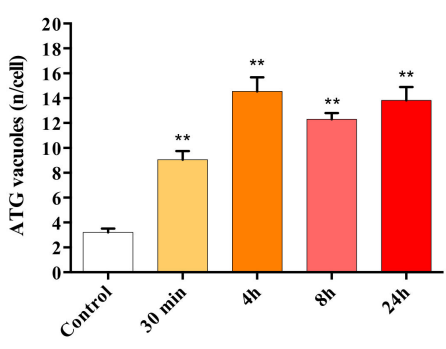

T1AM, $1 \mu M$

(k)

Figure 5. Transmission electron microscopy of U87MG cells. Representative pictures of -autophagy like vacuoles (arrows) in the cytoplasm in baseline conditions (a) and after treatment with $1 \mu \mathrm{M} \mathrm{SG}-1$, SG-2 or T1AM at 24h, (b-d). High magnification of different shaped autophagy like vacuoles (asterisk) in baseline conditions (e) and after treatment with 1 MM SG-1, SG-2 or T1AM at 24h (f-h). The mean number of autophagy -like vacuoles per cell was counted and values were reported in graph for each compound (i-k). The graphs show that all compounds induce a time-dependent increase in the number of autophagy -like vacuoles compared with baseline conditions. Values represent the mean \pm SEM of 30 cells for each group $(n=30)$. Comparisons between groups were made by using one-way ANOVA followed by a Dunnett's post-test. ${ }^{* *} p \leq 0.05$ compared with baseline conditions. Scale bars $(\mathbf{a}-\mathbf{d})=1 \mu \mathrm{m} ;(\mathbf{e}-\mathbf{g})=160 \mathrm{~nm}$.

As shown in representative panels (Figure 6), when LC3 and P20S immunogold staining was carried out concomitantly, the occurrence of both P20S and LC3 particles within the same organelle was documented in U87MG cells exposed to $1 \mu$ M SG-1, SG-2 or T1AM, suggesting that these compounds might modulate both autophagy and UP protein clearing pathways within the autophagoproteasomes.

Interestingly, the time dependent increase in LC3 + P20S positive autophagoproteasomes observed in U-87MG cells under the effect of $1 \mu \mathrm{M} \mathrm{SG}-1$, SG-2 or T1AM (Figure 6) perfectly overlaps with the increase in LC3 positive autophagy vacuoles originally observed by Bellusci et al. in U87MG cells exposed to the same treatment [13]. Therefore, increasing mTOR inhibition seems to produce a quite harmonic expression of both clearing pathways. 


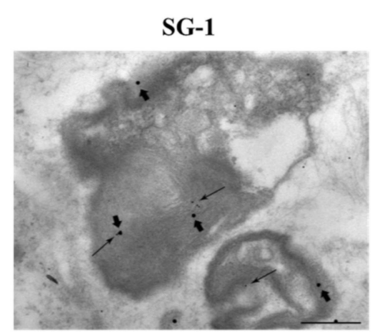

(a)

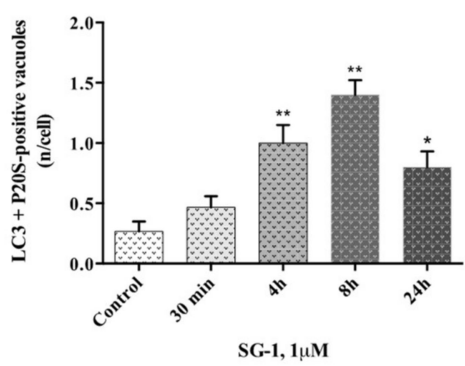

(d)

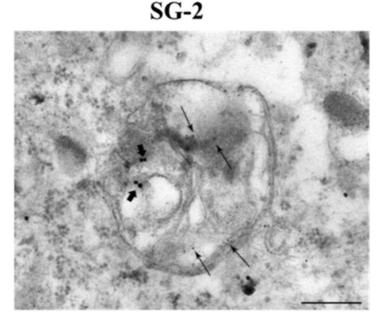

(b)

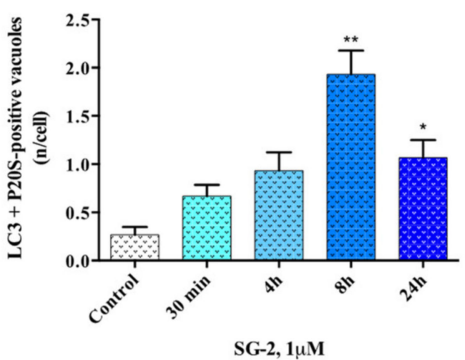

(e)

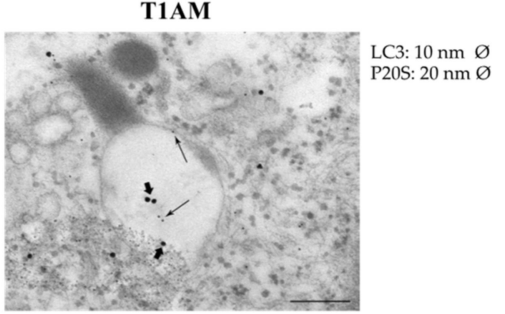

(c)

Figure 6. Occurrence of autophagoproteasome in U87MG cells after treatment with $1 \mu \mathrm{M} \mathrm{SG}-1$, SG-2 or T1AM. As shown in representative micrographs (a-c), when LC3 and P20S immunogold staining was carried out concomitantly the occurrence of both P20S particles and LC3 particles within the very same autophagy vacuoles was documented in U87-MG cells exposed to $1 \mu$ M SG-1, SG-2 or T1AM. In these pictures P20S staining is represented by $20 \mathrm{~nm}$ immunogold particles evidenced by arrowheads, while LC3 staining is represented by smaller $(10 \mathrm{~nm})$ immunogold particles evidenced by full thin arrows. After treatment with $1 \mu \mathrm{M}$ SG-1, SG-2 and T1AM the mean number of autophagoproteasomes occurring in the cell was counted, and as shown in graphs (d-f), a time-dependent increase of P20S+LC3 positive vacuoles was documented. Values represent the mean \pm SEM of 30 cells for each group $(n=30)$ Comparisons between groups were made by using one-way ANOVA followed by a Dunnett's post-test. ${ }^{*} P \leq 0.05,{ }^{* *} P \leq 0.01$ compared with baseline condition. Scale bars $(\mathbf{a}-\mathbf{c})=50 \mathrm{~nm}$.

\subsection{SG-2 Rescues LTP in hAPP-J20 Mouse Model of AD at the Level of the EC}

The evidence of pro-learning and antiamnestic effects elicited in mice by both T1AM and SG-2, along with their role in modulating autophagy, one of the potential therapeutic target processes in neurodegenerative diseases, encouraged us to pursue further investigations. Thus, we assessed the therapeutic potential of these molecules in the treatment of an experimental model of AD [32], a neurodegenerative condition which features early memory impairment.

In this study, we used a transgenic mouse model of $\mathrm{AD}$, which overexpresses alleles of the human APP gene (mhAPP mouse model) linked to familial AD [33]. These mice accumulate A $\beta$, beginning from entorhinal cortex (EC), which undergoes progressive neurodegeneration. Impairment of EC synaptic plasticity is an early sign of neuronal degeneration in mhAPP, which is evidenced by a loss of long term potentiation (LTP) expression [34].

Previous experiments showed that mhAPP slices, perfused with ACSF enriched with $5 \mu \mathrm{M}$ T1AM, regained LTP capacity after high frequency stimulation induction protocol (HFS) [18]. Notably, in a very recent work Accorroni et al. demonstrated that in the same experimental model co-administration of $5 \mathrm{nM}$ EPPTB, a selective TAAR1 antagonist, was able to revert the rescuing effects of T1AM on LTP [35], suggesting a role of TAAR1 as a possible drug target to ameliorate cognitive dysfunction in AD patients. Since SG2 is a recently developed T1AM analog endowed of almost comparable TAAR1 agonist properties (EC50 SG-2 $=240 \mathrm{nM}$; EC50 T1AM = $189 \mathrm{nM}$ ) [36], we hypothesized that it may have a similar effect, and we decided to administer this compound in the perfusion medium at different concentrations. 
In agreement with previous evidence, our experiments showed that LTP cannot be elicited by HFS in mhAPP slices perfused with ACSF alone (Figure 7). We then tried to rescue LTP in mhAPP slices using the SG2 compound. However, when used at the lowest concentration $(1 \mu \mathrm{M}), 10$ min perfusion with SG2 was not effective, and the mean amplitude after HFS was not significantly different from that of mhAPP exposed to ACSF alone $(0.87 \pm 0.06, n=7$, versus $0.93 \pm 0.044, n=9)$. In contrast, a higher concentration of SG2 $(5 \mu \mathrm{M})$, rescued LTP in mhAPP slices after HFS $(1.14 \pm 0.02, n=6)$ to a level that was significantly higher than that observed in mhAPP slices alone $(p<0.05)$, as well as in mhAPP slices perfused with SG2 $1 \mu \mathrm{M}(p<0.05)$ (Figure 7).

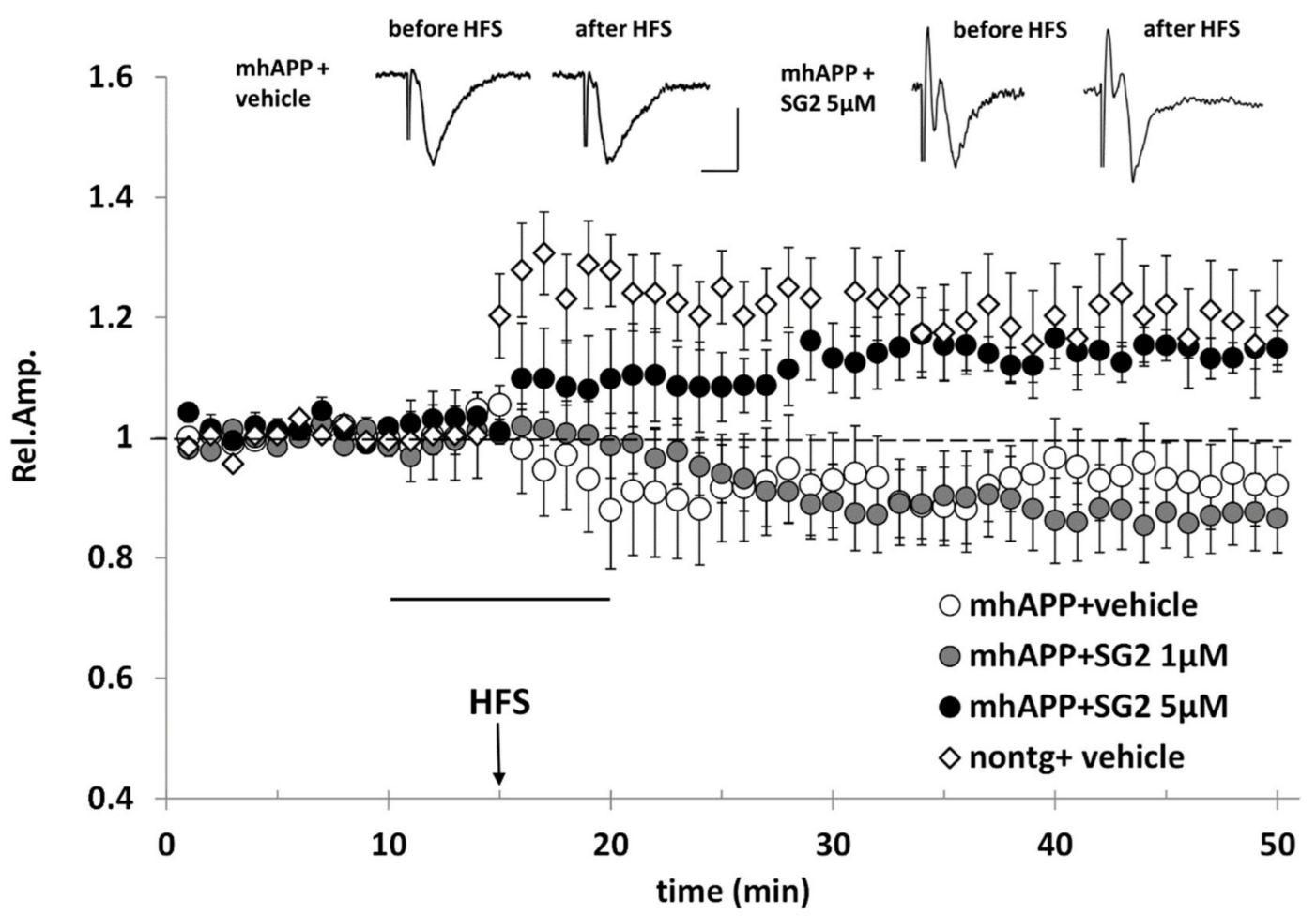

Figure 7. SG2 rescues LTP expression in the EC superficial layer of mhAPP mice. The LTP was induced by HFS stimulation in non-transgenic slices under ACSF (nontg + vehicle, white diamonds), whereas LTP expression was not elicited by HFS in mhAPP slices perfused with ACSF (mhAPP + vehicle, white circle) $(n=7)$. Perfusion of SG2 $5 \mu \mathrm{M}(5 \mu \mathrm{M}$, black circles, $10 \mathrm{~min}$ of application corresponding to the dark bar) rescued LTP expression in mhAPP slices $(n=6)$, whereas a lower concentration of SG2 $(1 \mu \mathrm{M}$, grey circles, $10 \mathrm{~min}$ of application corresponding to the dark bar) had no significant effect on mhAPP slices after HFS $(n=9)$. Error bars indicate SEM. Insert shows representative field potentials recorded either before or $35 \mathrm{~min}$ after HFS, in mhAPP slices under ACSF (mhAPP + vehicle, left) and in mhAPP slices under SG2 $5 \mu \mathrm{M}$ (mhAPP+SG2 $5 \mu \mathrm{M}$, right). Calibration bars: $1 \mathrm{mV}, 5 \mathrm{~ms}$.

\section{Discussion}

Neurodegenerative diseases are incurable multifactorial debilitating disorders of the nervous system that involve multiple pathways. Despite extensive efforts attempting to define the molecular mechanisms underlying neurodegeneration, many aspects of these pathologies remain elusive and no effective cures have been identified.

A common pathology shared by several neurodegenerative diseases is the accumulation of misfolded proteins. Given that autophagy is a cellular function that degrades abnormal proteins, including those that are misfolded, autophagy-inducing compounds are expected to mitigate the onset and progression of these diseases.

In the present study, we found that 3-iodothyronamine (T1AM), an endogenous component of the thyroid endocrine system originally identified as a potent trace amine associated receptor 1 
(TAAR1) agonist, and recently developed thyronamine-like TAAR1 agonists, SG-1 and SG-2, increase autophagy in U87MG cells by inducing the expression of SIRT6 to suppress the activities of Akt and leading to the inhibition of mTOR activities, with SG-2 showing higher potency as compared to SG-1. Moreover, from our assays, increasing mTOR inhibition seems to produce a harmonic expression of autophagy and UP clearing pathways in U87MG cells. Even though the detailed mechanisms for SIRT6 in regulating autophagy and its interplay with the UP clearing pathway need to be explored in future studies, we can speculate that, through the modulation of Sirt6 expression, T1AM and its analogs SG-1 and SG-2 might exert pleiotropic effects on energy metabolism and cell clearing pathways, which is likely to sustain neuroprotection.

Evidence that a $24 \mathrm{~h}$ treatment of human glioblastoma U87MG cells with $1 \mu \mathrm{M}$ T1AM, SG-1 or SG-2, didn't affect cell viability while increasing the expression of SIRT6, was provided. Notably, recent findings revealed that overexpression of SIRT6 can significantly affect glioblastoma cell growth and induce cell injury, resulting particularly evident 48 and $72 \mathrm{~h}$ after cell seeding [36]. In addition, T1AM and SG-2 have been previously shown to reduce cancer cells growth when used at high micromolar concentrations [37]. In our study, all compounds under investigation, showed a lack of cytotoxic effect in U87MG cells when treatment was extended to $72 \mathrm{~h}$ and the dose increased to $5 \mu \mathrm{M}$. This observation suggests that, at least in our experimental setting, SIRT6 activation doesn't cause human glioblastoma U87MG cells toxicity. Undeniably, future work will be required to ascertaining whether knocking down SIRT6 will thoroughly block out the autophagy induced by T1AM and SG-2 in U87MG cells and/or prevent the interplay between autophagy and UP protein degradation systems observed in the same cell line.

Our previous studies widely documented that SG-2 represents an effective functional mimic of T1AM with respect to TAAR1 agonistic activity [38], as well as to both metabolic and neurological effects $[13,20,21]$. In the present study, to further expand our knowledge on the pharmacological features of this novel T1AM analog (i.e. SG-2), we assessed the effects of SG-2 on the pathological alterations induced by $\mathrm{A} \beta$ in electrophysiological parameters, namely long term potentiation (LTP), in a transgenic mouse model of AD (mhAPP mouse) [32]. Indeed, the results obtained after testing the ability of SG-2 to restore LTP in mhAPP mouse showed that this molecule is also able to reproduce the protective effect of T1AM against $A \beta$ toxicity at the level of the entorhinal cortex (EC). This finding may also strengthen the role of TAAR1 as a possible drug target to ameliorate cognitive dysfunction in AD patients [35]. As a further expansion of this preliminary study, since protein homeostasis is crucial to sustain synaptic long-term plasticity and counteracting AD pathology, in future studies we will direct our attention to evaluate whether T1AM and SG-2 are also able to produce SIRT6-dependent activation of autophagy in the EC of mhAPP mice. Indeed, a better understanding of the underlying mechanisms of neuroprotective and cognitive-enhancing properties of T1AM and SG-2 may have an impact in AD field and indicate the way to novel therapeutic approaches, possibly bridging autophagy, weight loss and neuroprotection.

\section{Materials and Methods}

\subsection{Chemicals}

3-Iodothyronamine (T1AM), was kindly provided by Prof. Thomas Scanlan (OHSU, Portland, OR, USA) and was dissolved in 0.5\% DMSO (Veh). Thyronamine-like analogs SG-1 and SG-2, were synthesized by our group according a procedure previously described [38] and were dissolved in 0.5\% DMSO (Veh) to perform experiments with U87MG cells. To carry out experiments with animals, aliquots of SG-2 were stored at $-20^{\circ} \mathrm{C}$ in DMSO as a $6.8 \mathrm{mM}$ stock solution and diluted to the desired final concentration in artificial cerebrospinal fluid (ACSF), containing the following (in mM): $119 \mathrm{NaCl}$, $2.5 \mathrm{KCl}, 2 \mathrm{CaCl}_{2}, 1.2 \mathrm{MgSO}_{4}, 1 \mathrm{NaH}_{2} \mathrm{PO}_{4}, 6.2 \mathrm{NaHCO}_{3}, 10 \mathrm{HEPES}, 11$ glucose. 


\subsection{Cell Lines}

U87MG human glioma cell lines from Cell Bank (IRCC San Martino-IST, Genova, Itlay) were cultured in standard DMEM High Glucose medium (Sigma-Aldrich S.r.l., Milan, Italy) supplemented with 10\% fetal bovine serum (FBS), penicillin (50 IU/mL) and $100 \mathrm{mg}$ streptomycin (Sigma-Aldrich S.r.l.). Cells were kept at $37^{\circ} \mathrm{C}$ in a humidified atmosphere with $5 \% \mathrm{CO}_{2}$ and the medium was renewed two to three times per week.

For transmission electron microscopy (TEM), transcriptional analysis (qPCR) and Western blot (WB) assays, the cells were cultured at a density of $3 \times 10^{5}$ cells/well in a 6-well plate in a final volume of $2 \mathrm{~mL} /$ well.

Twenty-four hours after seeding, the cells were treated with test compounds (T1AM, SG1, and SG2) at the dose of $1 \mu \mathrm{M}$ for different exposure times $(0.5,4,8$, and $24 \mathrm{~h})$. Dilutions of test compounds were obtained by a stock solution ( $1 \mathrm{mM}$ in saline containing $10 \% \mathrm{DMSO})$.

\subsection{Assessment of Autophagy-Like Vacuoles, and Count of LC3 and P20S Immunogold Particles}

U87MG cells were fixed with a solution containing $2.0 \%$ paraformaldehyde and $0.1 \%$ glutaraldehyde in 0.1 M PBS ( $\mathrm{pH} 7.4$ ) for $90 \mathrm{~min}$ at $4{ }^{\circ} \mathrm{C}$. After removal of the fixing solution specimens were post-fixed in $1 \% \mathrm{OsO}_{4}$ for $1 \mathrm{~h}$ at $4{ }^{\circ} \mathrm{C}$, they were dehydrated in ethanol and finally embedded in epoxy-resin. For ultrastructural morphometry, grids containing non-serial ultrathin sections (90 nm thick) were examined at TEM, at a magnification of $8000 \times$. Several grids were analyzed in order to count a total number of 30 cells for each experimental group. We counted the number of autophagy vacuoles per cell as vacuoles with single, double or multiple membranes possessing the same electron density of the surrounding cytoplasm, or partly containing some electron dense structure [39]. In each cell we counted the number of autophagoproteasomes per cell as a single, double, multiple membrane vacuoles, in which immune-gold particles of LC3 (10 nm) and P20S (20 nm) were co-localized [39].

Post-embedding procedure was carried out on ultrathin sections collected on nickel grids, which were incubated on droplets of aqueous sodium metaperiodate $\left(\mathrm{NaIO}_{4}\right)$, for $30 \mathrm{~min}$, at room temperature in order to remove $\mathrm{OsO}_{4}$. Then grids were washed in PBS and incubated in a blocking solution containing $10 \%$ goat serum and $0.2 \%$ saponin for $20 \mathrm{~min}$, at room temperature. Grids were then incubated with the primary antibody solution containing both rabbit anti-LC3 (Abcam, Cambridge, UK, diluted 1:50) and mouse anti-P20S (Abcam, Cambridge, UK, diluted 1:20), 0.2\% saponin and 1\% goat serum in a humidified chamber overnight, at $4{ }^{\circ} \mathrm{C}$. After washing in PBS, grids were incubated in the secondary antibodies conjugated with gold particles (10 nm mean diameter, for gold particles anti-rabbit; $20 \mathrm{~nm}$ mean diameter, for gold particles anti-mouse, BB International) diluted 1:20 in PBS containing $0.2 \%$ saponin and $1 \%$ goat serum for $1 \mathrm{~h}$, at room temperature. In control sections, the primary antibody was not applied and they were incubated with the secondary antibody only. After washing in PBS, grids were incubated on droplets of $1 \%$ glutaraldehyde for 3 min; additional extensive washing of grids on droplets of distilled water was carried out to remove extensive salt traces and prevent precipitation of uranyl acetate. Finally, the grids were counterstained with a saturated solution in distilled water of uranyl acetate and lead citrate and observed by using a JEM SX100 electron-microscope (JEOL, Tokyo, Japan).

\subsection{Gene Expression Analysis}

Total RNA was extracted from U87MG cells using the Direct-zol RNA MiniPrep (Zymo Research, Irvine, CA, USA) following manufacturer protocol. An on-column DNaseI treatment was included. RNA concentration and purity were determined by Nanodrop-1000 spectrophotometer and Qubit v.1 fluorometer plus Qubit RNA HS Assay Kit (Thermo Fisher Scientific, Wilmington, DE, USA).

0.5. $\mu \mathrm{g}$ of total RNA were retrotranscribed in $20 \mu \mathrm{L}$ using QuantiTect Reverse Transcription kit (Qiagen, Hilden, Germany) following manual protocol indications. Relative quantity of gene 
transcripts was measured by real-time PCR on samples'cDNA using a SYBRGreen chemistry and an iQ5 instrument (Bio-Rad, Milano, Italy). Two $\mu \mathrm{L}$ of 5-fold cDNA dilutions and 8 pmol of each oligonucleotide were added to $10 \mu \mathrm{L}$ iTaq Universal SYBRGreen Supermix (Bio-Rad) in a $20 \mu \mathrm{L}$ total reaction volume. The PCR cycle program consisted of an initial $30 \mathrm{~s}$ denaturation at $95^{\circ} \mathrm{C}$ followed by 40 cycles of $5 \mathrm{~s}$ denaturation at $95^{\circ} \mathrm{C}$ and $15 \mathrm{sec}$ annealing/extension at $60^{\circ} \mathrm{C}$. A final melting protocol with ramping from $65{ }^{\circ} \mathrm{C}$ to $95{ }^{\circ} \mathrm{C}$ with $0.5{ }^{\circ} \mathrm{C}$ increments of $5 \mathrm{~s}$ was performed for verification of amplicon specificity and primer dimer formation.

Primers were designed with Beacon Designer Software v.8.0 (Premier Biosoft International, Palo Alto, CA, USA) with a junction primer strategy, whenever possible. In any case, negative control of retro-transcription was performed to exclude any interference from residual genomic DNA contamination. The primers sequence for RealTime-PCR are reported in Table 1.

Table 1. Primer sequences of target genes.

\begin{tabular}{|c|c|c|c|c|}
\hline $\begin{array}{l}\text { Reference Sequence } \\
\text { (RefSeq) mRNA }\end{array}$ & $\begin{array}{l}\text { Gene } \\
\text { Symbol }\end{array}$ & \multicolumn{2}{|c|}{ Sense and Anti-Sense Sequences } & $\begin{array}{l}\text { Length of the } \\
\text { Amplicon (bp) }\end{array}$ \\
\hline NM_001243084 & HIF1A & $\begin{array}{l}\text { sense } \\
\text { anti-sense }\end{array}$ & $\begin{array}{l}\text { TTGGCAGCAACGACACAG } \\
\text { GCAGGGTCAGCACTACTTC }\end{array}$ & $169 \mathrm{bp}$ \\
\hline NM_004958 & MTOR & $\begin{array}{l}\text { sense } \\
\text { anti-sense }\end{array}$ & $\begin{array}{c}\text { TGCCTTCACAGATACCCAGTA } \\
\text { AGACCTCACAGCCACAGA }\end{array}$ & $171 \mathrm{bp}$ \\
\hline NM_000546 & P53 & $\begin{array}{l}\text { sense } \\
\text { anti-sense }\end{array}$ & $\begin{array}{l}\text { TCAACAAGATGTTTTGCCAACTG } \\
\text { ATGTGCTGTGACTGCTTGTAGATG }\end{array}$ & $118 \mathrm{bp}$ \\
\hline NM_016539 & SIRT6 & $\begin{array}{l}\text { sense } \\
\text { anti-sense }\end{array}$ & $\begin{array}{l}\text { CTCCTCCGCTTCCTGGTC } \\
\text { TTACACTTGGCACATTCTTCC }\end{array}$ & 119 bp \\
\hline NM_002046 & GAPDH & $\begin{array}{l}\text { sense } \\
\text { anti-sense }\end{array}$ & $\begin{array}{l}\text { CССТTCATTGACСTCAACTACATG } \\
\text { TGGGATTTCCATTGATGACAAGC }\end{array}$ & $115 \mathrm{bp}$ \\
\hline
\end{tabular}

Efficiency and specificity of primers were tested making standard curves with fivefold serial dilutions of a cDNA obtained from a pool of all samples. The first dilution was the two-fold diluted cDNA. All reactions were run in duplicate. All samples were analysed in duplicate and averaged. The relative expression of the target gene was normalized to the level of GAPDH in the same cDNA. Samples were analyzed by the $2^{-\Delta \Delta \mathrm{Ct}}$ method, as described by Livak and Schmittgen [40].

\subsection{Western Blot Analysis and MTT Cell Viability Assay}

U87MG cells were seeded in 6-well plates $\left(3 \times 10^{5}\right.$ cells/well $)$ in a final volume of $2 \mathrm{~mL} /$ well and grown to $80 \%$ of confluence with standard medium (DMEM-high glucose). Cells were treated with vehicle (0.1\% DMSO) or test compounds (i.e. $1 \mu \mathrm{M}$ T1AM, SG-1, and SG-2) and incubated at $37{ }^{\circ} \mathrm{C}$ for $24 \mathrm{~h}$. After washing twice with ice-cold PBS cells were lysed and proteins $(20-30 \mu \mathrm{g})$ were separated on Criterion TGXTM gel (4-20\%) and transferred to Immuno-PVDF membrane (Bio-Rad). The membranes were probed overnight at $4{ }^{\circ} \mathrm{C}$ with primary antibodies [1:1000, SIRT6, m-TOR, p-mTOR, LC3, p62, and $\beta$-actin, (Cell Signaling), Euro Clone, Milan, Italy]. The primary antibodies were detected using peroxidase-coupled anti rabbit secondary antibody. The peroxidase was detected using a chemiluminescent substrate (ECL, Perkin Elmer, Milan, Italy). Immunoreactive bands were quantified performing a densitometric analysis with Image Lab Software (Bio-Rad) and normalized to $\beta$-actin. Cell viability was assessed by MTT reduction assay $24 \mathrm{~h}$ or $72 \mathrm{~h}$ after SG-1, SG-2 or T1AM application ( 1 or $5 \mu \mathrm{M})$ to U87MG cells seeded at a density of $1 \times 10^{4}$ cells per well of 96-well plates in $100 \mu \mathrm{L}$ of culture medium. Briefly, the reaction was started by adding $10 \mu \mathrm{L}$ of 3-(4,5-dimethylthiazol-2-yl)-2,5-diphenyltetrazolium bromide (MTT reagent; $5 \mathrm{mg} / \mathrm{mL}$ ) to the medium and the cells were incubated for $3 \mathrm{~h}$ at $37^{\circ} \mathrm{C}$. The resultant insoluble MTT-formazan dark red crystals were dissolved with $100 \mu \mathrm{L}$ of solubilization buffer $(10 \%$ SDS in $0.01 \mathrm{M} \mathrm{HCl})$ and after overnight incubation at $37^{\circ} \mathrm{C}$ absorbance at $570 \mathrm{~nm}$ was determined with a micro-plate reader (Bio-Rad 680).

\subsection{Animals}

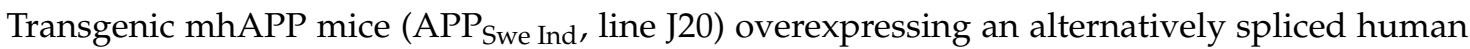
APP (hAPP) minigene that encodes hAPP695, hAPP751, and hAPP770 bearing mutations linked to 
familial AD (V717F, K670N/M671L) have been used for electrophysiological assays. Transgenic mice and their littermate controls (C57BL/6J), minimum 3 months of age, were from a colony kept in the animal facility of the IN-CNR, Pisa, Italy).

All experiments were conducted according to the Italian Ministry of Health guidelines (Legislative Decree n. 116/92) and in accordance with the European Community guidelines (European Directive 86/609/EEC). The experimental protocol (IACUC document) was approved by the Ministry of Health (n. 192/2000-A).

\subsection{In Vitro Electrophysiology}

Electrophysiology was performed as previously described ${ }^{19}$. Briefly, mice (C57BL-6J mice, Jackson laboratory, Bar Harbor, ME, USA) were anesthetized with urethane $(20 \%$ sol., $0.1 \mathrm{~mL} / 100 \mathrm{~g}$ body weight) i.p. injections and then decapitated (Italian Ministry of Health, IACUC, December 13, 2000). Horizontal slices containing the entorhinal area were cut using a vibratome (VT1200S, Leica, Milano, Italy). All steps were performed in ice cold oxygenated ACSF (mM: $119 \mathrm{NaCl}, 2.5 \mathrm{KCl}, 2 \mathrm{CaCl}_{2}$, $1.2 \mathrm{MgSO}_{4}, 1 \mathrm{NaH}_{2} \mathrm{PO}_{4}, 26.2 \mathrm{NaHCO}_{3}, 11$ glucose). Slices were then transferred to a chamber and perfused at a $2-3 \mathrm{~mL} / \mathrm{min}$ rate. Field potentials (FPs) were evoked by a concentric bipolar stimulating electrode in the layer II of EC. The recording pipette was placed in EC layer II. Basal recording was carried out using stimulus intensity evoking a response whose amplitude was $50-60 \%$ of the maximal amplitude. After $15 \mathrm{~min}$ of stable baseline, LTP was induced by high frequency stimulation (HFS, three trains of 100 pulses at $100 \mathrm{~Hz}, 10 \mathrm{~s}$ interval). After HFS, FPs were monitored every $20 \mathrm{~s}$ and averaged every 3 responses. The magnitude of LTP was calculated as the average of the relative amplitudes (compared to baseline) of FPs recorded in the last $10 \mathrm{~min}$. Values were expressed as mean \pm SEM percentage change relative to their mean baseline amplitude. Data collection and analysis were performed blindly by two different operators. SG2 compound ( $1 \mu \mathrm{M}$ or $5 \mu \mathrm{M})$ was added to ACSF perfusion and administered to slices for $10 \mathrm{~min}$, starting from $5 \mathrm{~min}$ before HFS.

\subsection{Statistical Analysis}

All data are reported as mean \pm SEM. Statistical analysis was performed by one-way analysis of variance (ANOVA), followed by Dunnett's and Tukey's multiple comparison tests. The threshold of statistical significance was set at $P<0.05$. Data analysis was performed by Graph-Pad Prism 6.0 statistical program (GraphPad Software Inc., San Diego, CA, USA).

For electrophysiological experiments statistical comparisons between experimental groups or between FP amplitudes measured during baseline and after the induction protocol were performed by applying a one-way repeated-measures ANOVA with pair wise multiple comparison procedures (Holm-Sidak method, Sigmaplot 12.0, Systat Software, Inc., Chicago, IL, USA).

Supplementary Materials: The following are available online, Figure S1: Full-length blots relative to the cropped images showed in Figure 3.

Author Contributions: Conceptualization, G.C. and F.F.; Investigation, L.B., M.R., V.C., S.S., F.F., F.S., P.L., S.R. and N.O.; Methodology, V.C. and N.O.; Supervision, G.C. and R.Z.; Writing - original draft, G.C.; Writing - review \& editing, F.F.. All authors have read and agreed to the published version of the manuscript.

Funding: This work was partly supported by grants from the University of Pisa Progetti di Ricerca di Ateneo (PRA_2017_55 to GC) and (PRA_2018-19_83 to RZ).

Conflicts of Interest: The author(s) declare that there is no conflict of interest.

\section{References}

1. Mazon, J.N.; de Mello, A.H.; Ferreira, G.K.; Rezin, G.T. The impact of obesity on neurodegenerative diseases. Life Sci. 2017, 182, 22-28. [CrossRef]

2. Procaccini, C.; Santopaolo, M.; Faicchia, D.; Colamatteo, A.; Formisano, L.; de Candia, P.; Galgani, M.; De Rosa, V.; Matarese, G. Role of metabolism in neurodegenerative disorders. Metabolism 2016, 65, 1376-1390. [CrossRef] 
3. Cai, D. Neuroinflammation and neurodegeneration in overnutrition-induced diseases. Trends Endocrinol. Metab. 2013, 24, 40-47. [CrossRef]

4. Lee, E.B.; Mattson, M.P. The Neuropathology of Obesity: Insights from Human Disease. Acta Neuropathol. 2014, 127, 3-28. [CrossRef]

5. Perluigi, M.; Barone, E.; Di Domenico, F.; Butterfield, D.A. Aberrant protein phosphorylation in Alzheimer disease brain disturbs pro-survival and cell death pathways. Biochim. Biophys. Acta (BBA)—Mol. Basis Dis. 2016, 1862, 1871-1882. [CrossRef] [PubMed]

6. Giblin, W.; Skinner, M.E.; Lombard, D.B. Sirtuins: Guardians of mammalian healthspan. Trends Genet. 2014, 30, 271-286. [CrossRef] [PubMed]

7. Kugel, S.; Mostoslavsky, R. Chromatin and beyond: The multitasking roles for SIRT6. Trends Biochem. Sci. 2014, 39, 72-81. [CrossRef] [PubMed]

8. Kaluski, S.; Portillo, M.; Besnard, A.; Stein, D.; Einav, M.; Zhong, L.; Ueberham, U.; Arendt, T.; Mostoslavsky, R.; Sahay, A.; et al. Neuroprotective Functions for the Histone Deacetylase SIRT6. Cell Rep. 2017, 18, 3052-3062. [CrossRef] [PubMed]

9. Scanlan, T.S.; Suchland, K.L.; Hart, M.E.; Chiellini, G.; Huang, Y.; Kruzich, P.J.; Frascarelli, S.; Crossley, D.A.; Bunzow, J.R.; Ronca-Testoni, S.; et al. 3-Iodothyronamine is an endogenous and rapid-acting derivative of thyroid hormone. Nat. Med. 2004, 10, 638-642. [CrossRef] [PubMed]

10. Scanlan, T.S. 3-Iodothyronamine (T1AM): A New Player on the Thyroid Endocrine Team? Endocrinology 2019, 150, 1108-1111. [CrossRef]

11. Haviland, J.A.; Reiland, H.; Butz, D.E.; Tonelli, M.; Porter, W.P.; Zucchi, R.; Scanlan, T.S.; Chiellini, G.; Assadi-Porter, F.M. NMR-based metabolomics and breath studies show lipid and protein catabolism during low dose chronic T(1)AM treatment. Obesity 2013, 21, 2538-2544. [CrossRef] [PubMed]

12. Assadi-Porter, F.M.; Reiland, H.; Sabatini, M.; Lorenzini, L.; Carnicelli, V.; Rogowski, M.; Selen Alpergin, E.S.; Tonelli, M.; Ghelardoni, S.; Saba, A.; et al. Metabolic Reprogramming by 3-Iodothyronamine (T1AM): A New Perspective to Reverse Obesity through Co-Regulation of Sirtuin 4 and 6 Expression. Int. J. Mol. Sci. 2018, 19, 1535. [CrossRef] [PubMed]

13. Bellusci, L.; Laurino, A.; Sabatini, M.; Sestito, S.; Lenzi, P.; Raimondi, L.; Rapposelli, S.; Biagioni, F.; Fornai, F.; Salvetti, A.; et al. New Insights into the Potential Roles of 3-Iodothyronamine (T1AM) and Newly Developed Thyronamine-Like TAAR1 Agonists in Neuroprotection. Front. Pharmacol. 2017, 8, 905. [CrossRef] [PubMed]

14. Cao, J.; Hou, J.; Ping, J.; Cai, D. Advances in developing novel therapeutic strategies for Alzheimer's disease. Mol. Neurodegener. 2018, 13, 64. [CrossRef]

15. Lenzi, P.; Lazzeri, G.; Biagioni, F.; Busceti, C.L.; Gambardella, S.; Salvetti, A.; Fornai, F. The Autophagoproteasome a Novel Cell Clearing Organelle in Baseline and Stimulated Conditions. Front. Neuroanat. 2016, 10, 78. [CrossRef]

16. Blasiak, J.; Pawlowska, E.; Szczepanska, J.; Kaarniranta, K. Interplay between Autophagy and the Ubiquitin-Proteasome System and Its Role in the Pathogenesis of Age-Related Macular Degeneration. Int. J. Mol. Sci. 2019, 20, 210. [CrossRef]

17. Accorroni, A.; Chiellini, G.; Origlia, N. Effects of Thyroid Hormones and their Metabolites on Learning and Memory in Normal and Pathological Conditions. Curr. Drug Metabalism 2017, 18, 225-236. [CrossRef]

18. Accorroni, A.; Criscuolo, C.; Sabatini, M.; Donzelli, R.; Saba, A.; Origlia, N.; Zucchi, R. 3-Iodothyronamine and trace amine-associated receptor 1 are involved in the expression of long-term potentiation in mouse entorhinal cortex. Eur. Thyroid J. 2016, 5 (Suppl. 1), 57-176.

19. Origlia, N.; Righi, M.; Capsoni, S.; Cattaneo, A.; Fang, F.; Stern, D.M.; Chen, J.X.; Schmidt, A.M.; Arancio, O.; Yan, S.D.; et al. Receptor for advanced glycation end product-dependent activation of p38 mitogen-activated protein kinase contributes to amyloid-beta-mediated cortical synaptic dysfunction. J. Neurosci. 2008, 28, 3521-3523. [CrossRef]

20. Chiellini, G.; Bellusci, L.; Sabatini, M.; Zucchi, R. Thyronamines and Analogues-The Route from Rediscovery to Translational Research on Thyronergic Amines. Mol. Cell. Endocrinol. 2017, 458, 149-155. [CrossRef]

21. Rogowski, M.; Bellusci, L.; Sabatini, M.; Rapposelli, S.; Rahman, S.M.; Chiellini, G.; Assadi-Porter, F.M. Lipolytic Effects of 3-Iodothyronamine (T1AM) and a Novel Thyronamine-Like Analog SG-2 through the AMPK Pathway. Int. J. Mol. Sci. 2019, 20, 4054. [CrossRef] [PubMed]

22. Nixon, R.A. The role of autophagy in neurodegenerative disease. Nat. Med. 2013, 19, 983-997. [CrossRef] [PubMed] 
23. Wei, Y.; Liu, M.; Li, X.; Liu, J.; Li, H. Origin of the Autophagosome Membrane in Mammals. Biomed Res. Int. 2018, 1012789. [CrossRef] [PubMed]

24. Condello, M.; Pellegrini, E.; Caraglia, M.; Meschini, S. Targeting Autophagy to Overcome Human Diseases. Int. J. Mol. Sci. 2019, 20, 725. [CrossRef]

25. Shao, J.; Yang, X.; Liu, T.; Zhang, T.; Xie, Q.R.; Xia, W. Autophagy induction by SIRT6 is involved in oxidative stress-induced neuronal damage. Protein Cell 2016, 7, 281-290. [CrossRef]

26. Iachettini, S.; Trisciuoglio, D.; Rotili, D.; Lucidi, A.; Salvati, E.; Zizza, P.; Di Leo, L.; Del Bufalo, D.; Ciriolo, M.R.; Leonetti, C.; et al. Pharmacological activation of SIRT6 triggers lethal autophagy in human cancer cells. Cell Death Discov. 2018, 9, 996. [CrossRef]

27. Takasaka, N.; Araya, J.; Hara, H.; Ito, S.; Kobayashi, K.; Kurita, Y.; Wakui, H.; Yoshii, Y.; Yumino, Y.; Fujii, S.; et al. Autophagy induction by SIRT6 through attenuation of insulin-like growth factor signaling is involved in the regulation of human bronchial epithelial cell senescence. J. Immunol. 2014, 192, 958-968. [CrossRef]

28. Zhong, L.; D’Urso, A.; Toiber, D.; Sebastian, C.; Henry, R.E.; Vadysirisack, D.D.; Guimaraes, A.; Marinelli, B.; Wikstrom, J.D.; Nir, T.; et al. The histone deacetylase Sirt6 regulates glucose homeostasis via Hif1alpha. Cell 2010, 140, 280-293. [CrossRef]

29. Brown, C.J.; Lain, S.; Verma, C.S.; Fersht, A.R.; Lane, D.P. Awakening guardian angels: Drugging the p53 pathway. Nat. Rev. Cancer 2009, 9, 862-873. [CrossRef]

30. Chang, J.R.; Ghafouri, M.; Mukerjee, R.; Bagashev, A.; Chabrashvili, T.; Sawaya, B.E. Role of p53 in neurodegenerative diseases. Neurodegener. Dis. 2012, 9, 68-80. [CrossRef]

31. Tasdemir, E.; Maiuri, M.C.; Galluzzi, L.; Vitale, I.; Djavaheri-Mergny, M.; D’Amelio, M.; Criollo, A.; Morselli, E.; Zhu, C.; Harper, F.; et al. Regulation of autophagy by cytoplasmic p53. Nat. Cell Biol. 2008, 10, 676-687. [CrossRef] [PubMed]

32. Magalingam, K.B.; Radhakrishnan, A.; Ping, N.S.; Haleagrahara, N. Current Concepts of Neurodegenerative Mechanisms in Alzheimer's Disease. Biomed Res. Int. 2018, 3740461. [CrossRef] [PubMed]

33. Mucke, L.; Masliah, E.; Yu, G.Q.; Mallory, M.; Rockenstein, E.M.; Tatsuno, G.; Hu, K.; Kholodenko, D.; Johnson-Wood, K.; McConlogue, L. High-level neuronal expression of abeta 1-42 in wild-type human amyloid protein precursor transgenic mice: Synaptotoxicity without plaque formation. J. Neurosci. 2000, 20, 4050-4058. [CrossRef] [PubMed]

34. Criscuolo, C.; Fontebasso, V.; Middei, S.; Stazi, M.; Ammassari-Teule, M.; Yan, S.S.; Origlia, N. Entorhinal Cortex dysfunction can be rescued by inhibition of microglial RAGE in an Alzheimer's disease mouse model. Sci. Rep. 2017, 7, 42370. [CrossRef]

35. Accorroni, A.; Rutigliano, G.; Sabatini, M.; Frascarelli, S.; Borsò, M.; Novelli, E.; Bandini, L.; Ghelardoni, S.; Saba, A.; Zucchi, R.; et al. Exogenous 3-iodothyronamine rescues the entorhinal cortex from $\beta$-amyloid toxicity. Thyroid 2019. [CrossRef]

36. Feng, J.; Yan, P.F.; Zhao, H.Y.; Zhang, F.C.; Zhao, W.H.; Feng, M. SIRT6 suppresses glioma cell growth via induction of apoptosis, inhibition of oxidative stress and suppression of JAK2/STAT3 signaling pathway activation. Oncol. Rep. 2016, 35, 1395-1402. [CrossRef]

37. Rogowski, M.; Gollahon, L.; Chellini, G.; Assadi-Porter, F.M. Uptake of 3-iodothyronamine hormone analogs inhibits the growth and viability of cancer cells. FEBS Open Bio 2017, 7, 587-601. [CrossRef]

38. Chiellini, G.; Nesi, G.; Digiacomo, M.; Malvasi, R.; Espinoza, S.; Sabatini, M.; Frascarelli, S.; Laurino, A.; Cichero, E.; Macchia, M.; et al. Design, Synthesis, and Evaluation of Thyronamine Analogues as Novel Potent Mouse Trace Amine Associated Receptor 1 (mTAAR1) Agonists. J. Med. Chem. 2015, 58, 5096-5107. [CrossRef]

39. Klionsky, D.J. Developing a set of guidelines for your research field: A practical approach. Mol. Biol. Cell 2016, 27, 733-738. [CrossRef]

40. Livak, K.J.; Schmittgen, T.D. Analysis of relative gene expression data using real-time quantitative PCR and the 2(-Delta Delta C(T)) Method. Methods 2001, 25, 402-408. [CrossRef]

(C) 2020 by the authors. Licensee MDPI, Basel, Switzerland. This article is an open access article distributed under the terms and conditions of the Creative Commons Attribution (CC BY) license (http://creativecommons.org/licenses/by/4.0/). 